
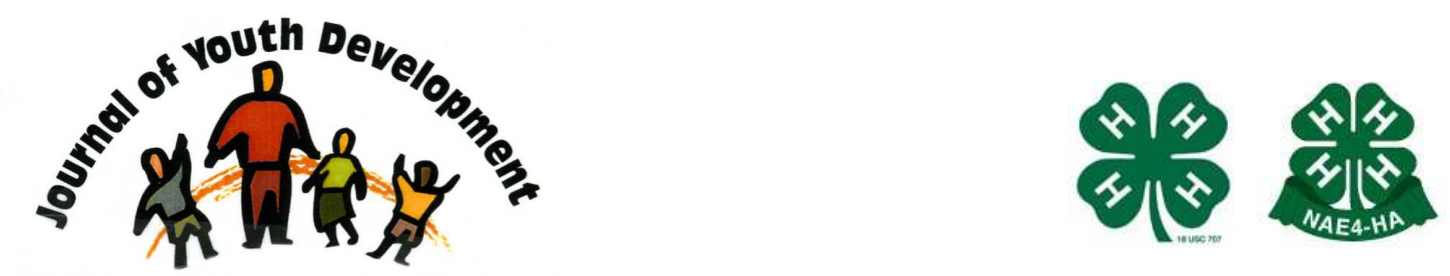

Bridging Research \& Practice

\title{
An Emerging Model of Knowledge for Youth Development Professionals
}

Femi Vance

University of California, Irvine

Irvine, $\mathrm{CA}$

fvance@uci.edu 


\title{
JOURNAL OF YOUTH DEVELOPMENT \\ bridging research and practice

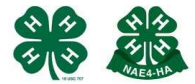

Volume 7, Number 1, Spring 2012

Article 120701FA003

\section{An Emerging Model of Knowledge for Youth Development Professionals}

\author{
Femi Vance \\ University of California, Irvine
}

\begin{abstract}
A model of knowledge for youth development professionals that is comprised of five knowledge domains: 1) Foundational Knowledge of Positive Youth Development; 2) Knowledge of Youth; 3) Knowledge of Group Facilitation; 4) Knowledge of Contexts and Organizational Systems and; 5) Specialized Youth Development Knowledge is proposed in this paper. The model is intended for use in youth development programs, which have been associated with better outcomes for participants when compared to other types of youth programs. The development of the knowledge base is framed by seminal research on teacher knowledge and informed by practiceoriented research in the out-of-school time field and literature on the quality of youth development programs.
\end{abstract}

\section{Introduction}

After-school programs are becoming more common in children's out-of-school time (OST) experiences. Research estimates that nearly 10 million children participate in youth programs annually (Yohalem, Pittman, \& Edwards, 2010) and increasingly, these programs are regarded as developmentally enriching contexts, where youth can be nurtured academically, socially, emotionally and civically (Bodilly \& Beckett, 2005; Durlak \& Weissburg, 2007; Grossman et al., 2002; Little \& Harris, 2003; Miller, 2003; Vandell et al., 2005; 2006). Experts and practitioners assert that program staff or youth practitioners are critical in shaping programs into contexts that promote positive development (Birmingham, Pechman, Russell \& Mielke, 2005; Bowie \& Bronte-Tinkew, 2006; Stone, Garza, \& Borden, 2004) and researchers in the after-school field acknowledge the importance of staff by including staff background, education, and training in definitions of program quality (Vandell, Reisner, Brown, Pierce, Dadisman, \& Pechman, 2004).

Despite the central role of program staff in delivering quality youth programs, the field is just beginning to examine the practices of these educators. An important component of this practice-oriented research is an understanding of the knowledge that these professionals draw 
upon during their daily work (e.g. Larson, Hansen, \& Walker, 2005; Larson \& Walker, 2010; Walker \& Larson, 2006). Unfortunately, very little is known about the professional knowledge base that staff use to inform their practices. The purpose of this paper is to begin to articulate the knowledge used by program staff when implementing high quality programs.

Researchers of formal schooling are far more advanced in their understanding of the knowledge and instructional practices that are effective in classrooms than scholars in the youth development field are about youth practitioners. The literature on teacher education describes a knowledge base that supports effective teaching (Shulman, 1986; Wilson, Shulman, \& Richert, 1987 ) that has influenced research, practice, and the professionalization of teaching (Ball, Thames, \& Phelps; 2008).

As educators in non-formal educational environments, youth practitioners also have a knowledge base that guides their practice but that has yet to be defined for the field. The importance of explicitly articulating this knowledge base for program staff is three fold.

- First, a knowledge base that is grounded in theory and empirical research will help youth practitioners perform in ways that support the developmental goals of the programs in which they work. In a policy climate that demands evidence of the effectiveness of youth programs, refining staff practices to enhance the healthy development of children and adolescence is critical, not only for program participants but also for the sustainability of youth programs.

- Second, a deeper understanding of the professional knowledge base of program staff can contribute to the professionalization of the youth development field by describing the disciplinary expertise that should be acquired to work in the field. Research can contribute to the development of this disciplinary expertise by exploring the relationships between youth practitioners' knowledge and their practice.

- Third, advancing a knowledge base for program staff will move the field toward a common language about the work of supporting healthy development in the out-ofschool time hours. A common language can then be used to focus and guide discussion and reflection among program staff to improve practices (Stone, Garza, \& Borden, 2004).

This paper moves forward with the important work of defining the knowledge base for youth practitioners with the intention of stimulating scholarly dialogue in the youth development field about this issue.

Before beginning, let's clarify for whom this knowledge base is intended. The ensuing knowledge base was developed for adults who work in youth development programs. Professionals who work with youth have multiple job titles (National Institute for Out-of-School Time, 2006), such as youth workers, youth practitioners, and after-school professionals to name a few. The remainder of this paper will not use any titles that do not suggest that specialized knowledge or practice is needed to deliver quality youth programs (i.e. youth worker or youth practitioner). Instead, youth development (YD) professionals will be used to refer to program staff in informal educational settings. This title identifies a specific field (youth development) and denotes expertise (professional) within that field. Huebner, Walker, and McFarland (2003) define YD professionals as individuals who work in informal educational settings that provide opportunities and supports for the healthy development of children and adolescents. YD professionals can serve at multiple levels of youth-serving organizations (YSO) providing direct service and/or developing and managing programs. 
YD professionals work in a variety of settings but this paper focuses on the knowledge needed to work in youth development programs. Much like the terms used for YD professionals, the definition of a youth development program varies and researchers and practitioners are still developing a clear, succinct definition. In this paper, a youth development program refers to a program whose goal is to promote positive youth outcomes and prevent risky behaviors in youth. Positive outcomes are when youth build competencies in key developmental areas such as educational attainment, health and safety, social and emotional development, and selfsufficiency (Hair, Moore, Hunter, Kaye, 2002). In contrast, risky behaviors are those that hinder positive outcomes, such as substance abuse and poor school attendance, that can lead to maladjustment. Youth development programs achieve their dualistic goal by providing "supportive and empowering environments where activities create multiple opportunities for a range of skill-building and horizon-broadening experiences" (Roth \& Brooks-Gunn, 2003a, p.110). While the model of knowledge described in this paper is intended for YD professionals working in youth development programs it may also be applicable in other organized activities, such as sports, mentoring, or tutoring.

The pages that follow delineate a model of knowledge for YD professionals beginning with a review of the research on teacher knowledge to provide a theoretical lens and organizational framework. This is followed by a description of the practices of YD professionals that support the goals of positive youth development programs. Then the emerging model of knowledge is presented through an examination of the literature on the practice of YD professionals and research about high-quality youth programming. The paper closes with directions for future research.

\section{Conceptual Framework}

Models of knowledge for classroom teachers became popular after Lee Shulman's seminal piece, Those Who Understand: Knowledge Growth in Teaching (1986), in which he presented the first model of teacher knowledge. According to Shulman (1986), there are three interrelated domains of teacher knowledge that support effective teaching and the consequent student learning.

- The first domain, content knowledge, is an understanding of the facts and concepts of a particular subject matter and an understanding of how key principles are organized and how new knowledge is legitimized.

- Curricular knowledge, the second domain, is an understanding of the purpose, strengths, and limitations of the available curricular tools used to teach a given topic. Strong curricular knowledge also requires that teachers have an understanding of the curriculum used for different skill levels and how the curriculum relates to other topics encountered by students.

- The final and most complex domain, pedagogical content knowledge (PCK), refers to knowledge about teaching a specific subject matter and includes methods of representing concepts clearly to others, understanding what promotes or hinders learning a specific topic, and which instructional strategies will foster understanding in students.

In later work, Wilson et al. (1987) continued to articulate how this knowledge base is used by teachers and its implications for practice. They argued that teachers draw on their knowledge to "transform content for the purposes of teaching....and to foster the development of subject matter knowledge in students" (p. 110). In other words, the model of teacher knowledge 
describes what teachers should know to support student learning. Shulman (1987) and his colleagues (e.g. Shulman \& Sykes, 1986) continued to refine his initial model of teacher knowledge and later the model was expanded to include a knowledge of: (a) general pedagogy such as classroom management and structure; (b) students' characteristics; (c) educational goals; (d) educational contexts from classroom to neighborhood culture; and (e) other content.

This revised model stimulated a wealth of scholarly inquiry. During this time, the model of teacher knowledge continued to evolve with empirical evidence that both supported and revised the models set forth by Shulman and his colleagues. Carlsen's (1999) examination of PCK and related domains of teacher knowledge is the most useful for identifying agreement across studies and across time. His analysis reveals that the most consistent domains in the model of teacher knowledge are (a) general pedagogical knowledge; (b) content knowledge; (c) pedagogical content knowledge; (d) curricular knowledge; (e) knowledge of educational goals; and (f) knowledge of students. More recently, Ball, Thames, and Phelps (2008) found evidence of two new domains of content knowledge (common content knowledge and specialized content knowledge) and two additional domains of pedagogical content knowledge (knowledge of content and students and knowledge of content and teaching) from a practice-oriented exploration of teacher instruction in mathematics classrooms.

The evolving model of teacher knowledge has been and continues to be constructive for the teaching profession. The impact of Shulman's work on teacher education, professional development initiatives, and teacher practice is particularly notable. Teachers report professional development that addresses content knowledge as being useful to their work (Scribner, 1999) and strengthening the focus on content knowledge in teacher professional development is considered an effective training strategy (Garet, Porter, Desimone, Birman \& Yoon, 2001). As for the practice of teaching, Ball et al. (2008) credit Shulman's work with helping professionalize teaching by highlighting a specialized knowledge that is used to educate students and influence quality standards for the profession. They also assert that Shulman's work created a link between knowledge and practice by demonstrating that both are needed to develop pedagogical content knowledge, the specialized domain of knowledge for teaching a specific subject. The influence of the model of teacher knowledge is far-reaching and serves as an example of the types of advances that could occur within the youth development field as a result of scholarly dialogue about the knowledge used by YD professionals.

The value of the model of teacher knowledge also lies in its definition and organization. Broadly, a model of knowledge can be described as a tool that identifies and defines the knowledge that is central to a profession. Moreover, the tool is organized to easily identify individual domains of knowledge and to distinguish them from one another. Perhaps some scholars will argue that the model of teacher knowledge has more to offer the youth development field than just definition and organization and imply this model can also be applied to the work of YD professionals. It is likely that there will be similarities between the domains of teacher knowledge and those to be described for YD professionals due to a shared goal; that is to nurture learning and development in children and adolescents. Yet, within this goal of promoting healthy development, differences exist between teaching and youth development programs. In school settings, academic and cognitive development tends to take precedence over growth in other developmental areas. In contrast, youth development programs adopt a more holistic approach and explicitly address multiple developmental areas in their interactions with youth. The nuanced differences between the developmental goals of teaching and youth development programs suggest that there will be differences between the model of teacher knowledge and the one for YD professionals. The distinct contexts in which youth development programs are 
implemented is another difference that prohibits direct application of the model of teacher knowledge to YD professionals. Teachers and YD professionals tend to work in contrasting (although we hope complementary) contexts with their own opportunities and constraints that require specific types of knowledge.

In comparison to the teaching literature, there is minimal research in the youth development field that discusses the knowledge used by YD professionals. The available literature is limited because of its narrow focus on a specific program model (e.g. Stone \& Rennekamp, 2004) and/or a heavy emphasis on skill and circumscribed use of current research (Vance, 2010). Therefore, the literature on staff practices and quality youth programming is examined to identify individual domains of knowledge that can be combined to form a knowledge base for YD professionals.

\section{Approach to the Literature Review}

The model of knowledge for YD professionals is developed, in part, by adopting a data driven approach used in the research on teacher education. Ball and Cohen (1999) argue that "teaching happens in the particulars" (p.10) and that much of what teachers need to know can be learned during and from practice. From this perspective, it may be possible to identify the knowledge that teachers use from the particulars of their work. It follows then that consulting literature that focuses on the substance of YD professionals' work with young people can identify the knowledge domains that they use. Much of this type of literature comes from qualitative research on youth programs.

At the same time a theory driven approach is used in which empirical research and theoretical articles about the quality of youth development programs are reviewed. This approach was informed by a characteristic of effective teacher professional development. Hawley and Valli (1999) identified eight features of high quality professional development; one of which is to provide links between formal knowledge and theory (acquired through research and academic study) and practical knowledge and skills. This characteristic of effective professional development underscores the importance of opportunities for practitioners to engage with the theoretical and empirical foundations of their field. Therefore, this paper draws on theoretical articles that have an explicit youth development focus as well as the body of research on the quality of youth programs. By taking both a data driven and theory driven approach, this paper attempts to gain insight from blending the knowledge from both research and practice, demonstrating a respect for each to contribute equally to the youth development field. Before presenting the emerging model of knowledge the central tasks of youth development work are highlighted.

\section{The Practice of Youth Development Professionals}

At its core, the practice of YD professionals is about designing and implementing program activities (that usually occur in groups) that provide youth with opportunities for learning and development (Astroth, Garza, \& Taylor, 2004; Huebner et al., 2003). Program activities serve to attract youth to the program and keep them engaged (Benson, Scales, Hamilton, Sesma, Hong, \& Roehlkepartain, 2006; Larson, et al., 2004; Larson \& Walker, 2010; Roth \& Brooks-Gunn, 2003a; 2003b; 2003c). These activities tend to be structured and the specific content of each activity is secondary to the types of learning opportunities and developmental supports that are provided (Roth \& Brooks-Gunn, 2003a; 2003b; 2003c). In fact, the specific content will have to be tailored to the community, culture, interest, and other individual characteristics of youth which means no one type of content is paramount (Roth \& Brooks-Gunn, 2003a; 2003b; 
2003c). The literature highlights the specific features that program activities should posses to achieve the goal of enhancing learning and providing developmental supports for youth.

First, YD professionals should design program activities that meet the specific developmental needs of the young people that they serve so that the activities are appropriately challenging for youth (Camino \& Zeldin, 2002; Larson, Hansen et al., 2005; Yohalem, 2003). A review of evaluation findings for youth development programs found that the programs that successfully improved youth outcomes were also those that had explicit focus on the developmental needs of their participants (Catalano, Berglund, Ryan, Lonczak, \& Hawkins, 2004). This finding suggests that YD professionals should have a thorough enough understanding of child and adolescent development to design activities that can address the developmental needs of their youth.

Second, the literature suggests that programs should encourage youth to direct their own learning through their thoughts, actions, and interactions (Benson et al., 2006; Hamilton, Hamilton, \& Pittman, 2004; Larson, Hansen, et al., 2005). This type of active learning has been associated with building competencies and a drop in risky behaviors (Benson et al, 2006). One way that YD professionals can encourage active learning is to facilitate youth-adult and youthyouth partnerships (Camino, 2005; Larson \& Walker, 2005; Larson Walker, \& Pearce; 2005). Some evidence suggests that quality youth-adult partnerships can lead to youth empowerment and skill development in targeted areas (Larson, Walker, et al., 2005). Furthermore, youth report that working in contexts that provide opportunities to collaborate with adults and peers enhance $21^{\text {st }}$ century skills like initiative, time management, and the ability to work in teams (Dworkin, Larson, \& Hanson; 2003).

Partnerships with adults and peers should give young people opportunities to work with others in ways that encourage their input and builds upon their strengths while also teaching them new skills (Huebner et al., 2003). Forming and maintaining these partnerships can be difficult because there does not appear to be a one size fits all approach, nevertheless, research offers some promising strategies. Camino (2005) asserts that strong youth-adult partnerships are likely to form when adults and youth work alongside one another to achieve collective goals such as finishing a project. Larson, Walker et al. (2005) contend that adults who facilitate these partnerships should understand "youths' cultural framework, developmental levels, preferences, and other group and individual factors" (p.71) to help establish connections with youth and facilitate connections between youth. YD professionals can also incorporate knowledge about youths' everyday lives into activities as well as knowledge about the multiple contexts that youth encounter on a daily basis (e.g. families, schools, and neighborhoods) to promote collaboration and involvement in activities (Stein, Wood, Walker, Kimball, Outley, \& Baizerman, 2005; Walker, Marczak, Blyth, \& Borden, 2005). One challenging aspect of managing these partnerships is maintaining a professional relationship with youth that is also personal enough to inspire connection and build trust (Larson \& Walker, 2010; Walker \& Larson; 2006).

Third, Roth and Brooks-Gunn (2003a; 2003b; 2003c) argue that program activities that are authentic, provide opportunities for skill-building, broaden youths' horizons, and improve developmental supports in multiple contexts are the ideal for youth development programs. Authentic activities are challenging for youth and connect to real life experiences such as future employment and conflict resolution. Determining which activities will be considered challenging will depend on the developmental needs of youth. Skill building activities are those that provide opportunities for youth to hone or develop new skills. Activities that broaden horizons expose young people to new experiences, people, places and ideas. Finally, activities should increase 
developmental supports in multiple contexts (e.g. school and family), by attempting to change the norms, attitudes, or skills of adults in other settings. Examples of such activities are parenting classes or teacher training. This fourth feature complements what the National Research Council (NRC) and Institute of Medicine (IOM) (2002) has termed integration in which programs work with families, schools, and other community organizations to provide and coordinate developmental opportunities for youth. Roth and Brooks-Gunn (2003b; 2003c) found few programs that exhibited all four characteristics, however, they represent exemplary features of activities in youth development programs.

In addition to implementing program activities, YD professionals must also manage the program atmosphere, which serves as the backdrop for their daily work with young people. YD professionals should establish a program atmosphere that is supportive and empowering (Roth \& Brooks-Gunn, 2003a; 2003b; 2003c) and includes positive group culture and social norms (Larson \& Walker, 2010). Establishing and maintaining youth-adult and youth-youth partnerships are critical to developing a supportive atmosphere and youth participation is necessary to create an empowering environment. This emphasizes the importance of peer and adult partnerships. Moreover, youth development programs that exhibit positive group norms were more likely to achieve the developmental goals of their programs (Catalano et al., 2004). Creating prosocial norms requires that YD professionals set realistic behavioral expectations and also hold youth accountable for meeting them. To that end, YD professions must constantly negotiate the balance between promoting norms and maintaining consistent expectations (Larson \& Walker; 2010).

Another important aspect of YD professionals' work is interacting with the organizations and systems that influence youths' daily lives and how they experience the program. Larson and Walker (2010) conducted program observations and interviews to understand the dilemmas faced by YD professionals. They found that struggling with the influence that other contexts had on program implementation was a common predicament encountered by YD professionals. For example, YD professionals had to address parental concerns about the program, be aware of personal and school activities that limit youths' participation, and support youth as they negotiate relationships with adults outside of the program. In addition, YD professionals also had to learn to work within organizational priorities and constraints, such as limited resources, to provide youth with enrichment activities. This may also entail explaining these constraints and priorities to young people.

The above description focuses only on the central tasks performed by YD professionals, it does not encompass every aspect of the profession. In fact, YD professionals report juggling multiple roles within their organizations (Madzey-Akale \& Walker, 2000) such as recruiter, advocate, volunteer coordinator, and fundraiser (Yohalem, Pittmann \& Moore, 2006). Yet, the focus of this paper is not on the multiple roles performed by YD professional; instead the intent is to articulate the knowledge that is necessary for the central tasks of the daily work with youth.

In summary, these central tasks include:

- Designing program activities

- Building relationships with youth and supporting the development of peer relationships

- Involving youth in their own learning and

- Establishing a supportive and empowering atmosphere including positive expectations and social norms. 
It is these central tasks that the model of knowledge for YD professionals is intended to inform.

\section{Emerging Model of Knowledge for Youth Development Professionals}

The proposed model of knowledge consists of five domains: 1) Foundational Knowledge in Positive Youth Development 2) Knowledge of Youth; 3) Knowledge of Group Facilitation; 4) Knowledge of Contexts and Organizational Systems and; 5) Specialized Youth Development Knowledge. Each domain is described in Figure 1. below.

Figure 1

Model of Knowledge for Youth Development Professionals

\begin{tabular}{|l|}
\hline Foundational Knowledge in \\
Positive Youth Development \\
- PYD Goals and vocabularies \\
- Developmental process of \\
- youth (6-20 yrs) \\
- PYD principles \\
- Em approach to practice \\
theories \\
\hline
\end{tabular}

\begin{tabular}{|ll|}
\hline & Knowledge of Youth \\
- & Developmentally \\
- & Culturally \\
- Experientially \\
Personally \\
\end{tabular}

\begin{tabular}{|c|c|}
\hline \multicolumn{1}{|c|}{ Specialized Youth } \\
Development Knowledge \\
- Topical Knowledge \\
- $\quad$ Experiential \& \\
Collaborative \\
Pedagogy \\
- S.A.F.E Activities \\
\hline
\end{tabular}

Knowledge of Group Facilitation

- Support youth skill building

- Provide structure for youth involvement

- Share responsibility with youth

- Modeling thinking for youth
Knowledge of Contexts and organizational Systems

- Features of high quality youth programs

- Knowledge of opportunities and constraints presented by schools, families, and community partners

\section{Foundational Knowledge of Positive Youth Development}

The foundational knowledge of positive youth development (PYD) can best be described as a deep understanding of the multiple dimensions of PYD theory, particularly how it relates to practice. The proposed components of foundational knowledge are discussed below.

Positive Youth Development Goals and Vocabularies. The PYD philosophy underlies the practice of YD professionals. Broadly, the goal of PYD theory is to foster healthy development in young people by supporting youth through the developmental process in ways that build upon their strengths and reduces risky behaviors (Benson et al., 2006; Roth \& Brooks-Gunn, 2003a). This broad goal has been characterized using different vocabularies (Benson et al., 2006). Two of 
the most common and widely research PYD vocabularies include the Forum for Youth Investment's 5 C's (Lerner, 2005; Phelps, Zimmerman, Warren, Jelicic, von Eye, \& Lerner, 2009; Pittman, Irby, \& Ferber, 2001) and the Search Institute's developmental assets (Benson, 2003; NRC \& IOM, 2002). According to the 5 C's, the goal of PYD is for youth to strengthen their character, display competence and confidence, develop connections with adults and peers, and show caring for others (Pittman et al., 2001). A sixth C, contribution to self, family, and community is thought to develop when the five Cs are sustained over an extended period of time (Lerner, 2005; Pittman et al. 2001). Some evidence suggests that participation in youth programs can improve the 6 C's in young adolescents (Lerner, 2005; Phelps et al., 2009).

In contrast, developmental assets are individual strengths (internal) and ecological (external) supports that promote healthy development (Hamilton et al., 2004). From a PYD perspective, the goal is to increase the number of internal and external assets of youth. There is still some debate in the field about the number of developmental assets, however, the most established are the 40 assets set forth by the Search Institute (Benson, 2003). In their asset framework The Search Institute outlines 20 external and 20 internal assets (Benson, 2003). The external assets are divided into four broad categories including support, empowerment, boundaries and expectations, and constructive use of time. Similarly, the internal assets are divided into four broad categories; positive values, commitment to learning, social competencies, and positive identity. Youth should experience multiple internal and external assets across each of the eight sub-categories to maximize their benefits. Other researchers have found far fewer than 40 developmental assets. For example, Theokas et al. (2005) identified 14 developmental assets among a sample of 100,000 early adolescents. Nonetheless, research on developmental assets demonstrates that as youth experience more assets they are more likely to exhibit positive outcomes and less likely to engage in risky behaviors (Benson, 2003). Youth development programs are one context that provides external assets and opportunities for youth to build their internal assets (Lerner, 2005).

The positive links between participation in youth development programs and the development of the 5 C's and building developmental assets highlight the importance of the PYD approach to the practice of YD professionals. They should be aware of and have an understanding of the different vocabularies used to discuss the developmental goals of the PYD approach. Two have been mentioned here but there are others that exist in the field that may be relevant (Benson et al., 2006; Theokas et al., 2005). For example, behaviors associated with thriving have also been related to the PYD theory (King, et al., 2005; Theokas et al., 2005).

Positive Youth Development: Process, Principles, and Practice. Early contributors to the development of PYD asserts that the term "youth development" can be used in three different ways; as a process, as principles, and as a practice that shares common goals (Hamilton et al., 2004). YD professionals should understand each of the three facets of youth development. Hamilton et al. (2004) used the term process to refer to the developmental process from childhood (age 6) to young adulthood (approximately age 20) that encompasses cognitive, physical, social, emotional, and moral growth. YD professionals will rely on knowledge of the developmental process to shape program environments and design activities that meet the needs of youth.

The principles of PYD are also essential to the central tasks of YD professionals. These principles include:

a) committing to fostering healthy development in youth;

b) acknowledging that all youth need support for healthy development;

c) using supportive relationships and challenging activities as developmental tools; 
d) emphasizing the strengths of young people; and

e) actively engaging youth in their own growth (Hamilton et al., 2004).

Lerner (2005) posits that another defining principle of PYD theory is that healthy development is promoted and problem behaviors minimized when the strengths of adolescents match the supports available within a given context.

Practice, the third facet of youth development, is guided by the aforementioned principles and occurs at two different levels; in systems and in settings (Hamilton et al., 2004). At the systems level, practice is referred to as community youth development where organizations and institutions are connected to provide a range of contexts and resources that support the process of development (Camino \& Zeldin, 2002; Hamilton et al., 2004). Benson (2003) refers to communities engaged in the intentional effort of youth development as asset-building communities. In their daily work YD professionals are entrenched in the community (or system) and may not recognize the integral role that they play in community youth development efforts (Camino \& Zeldin, 2002). A knowledge of community youth development could broaden YD professionals' view of the field and expose them to potential careers working with and/or on behalf of youth.

The second level of practice occurs in settings or the locations where individual programs are implemented (Hamilton et al., 2004; Smith, Peck, Denault, Blazeveski, \& Akiva, 2010). Settings are where YD professionals must use their knowledge to promote positive development in young people, where activities are designed around developmental processes, where collaboration builds relationships, where strengths are celebrated and skills sharpened, and where youth are invited to participate in this growth. While this may seem obvious it is worth noting YD professionals should have a comprehensive knowledge of the setting(s) in which they deliver programming.

Emerging Theories of Practice. PYD is a relatively new theory that has found the most traction within the youth development field. As the field matures other theories may unfold that YD professionals should learn about. One such example is the Theory of Developmental Intentionality (TODI) (Walker et al, 2005). TODI is an emerging theory that is based on youth development principles and informed by more classic developmental theories such as Vygostsky's (1962) zone of proximal development and Eccles and Midgely's (1989) stageenvironment fit. TODI offers a concise description of how practice guided by the PYD philosophy matters for youth outcomes. TODI posits that youth engagement occurs when programs intentionally foreground youths' developmental needs by providing a fit between their needs and program content. Over time, youth's engagement leads to positive developmental processes. As youth take note of their own positive development they are motivated to continue their engagement with the program and this eventually leads to long-term positive outcomes for youth.

In summary, foundational knowledge is a deep understanding of PYD theory whereby YD professionals would be well versed in the different vocabularies used to describe the goals of PYD, the developmental processes of youth, the key PYD principles, and the implications for practice. The foundational knowledge also includes being grounded in emerging developmental theories that can guide what Larson et al. (2004) calls "the art" of practice in the youth development field. Two approaches that could be used to strengthen foundational knowledge are to engage with the literature on PYD and seek exposure to programs that adopt an explicit PYD approach in their practice. 


\section{Knowledge of Youth}

Knowledge of youth is important for designing challenging activities that will attract youth and retain their interest. (Lauver, Little \& Wiess, 2004). Knowledge of youth is also critical for nurturing supportive relationships with young people. The literature points to four different ways in which YD professionals should know young people. That is, they should know them, (1) developmentally; (2) culturally; (3) experientially and; (4) personally.

In foundational knowledge, PYD and TODI were presented as theories that should underlie the practice of YD professionals. These theories make it clear that YDPS should keep the developmental needs of young people central as they design learning environments and program activities. In essence PYD and TODI indicate that YD professionals should have a broad understanding of the developmental processes of children and youth. Yet, the description of the central tasks indicates that they should also understand the specific developmental needs of the young people that they serve. In other words, YD professionals should be experts on their youth. This requires a thorough understanding of the developmental needs of the age group they work with the most. For some YD professionals this means elementary students and adolescents for others. To have a thorough knowledge of students, a YD professional should have both; a broad understanding of the child and adolescent development with an emphasis on the developmental period that corresponds to the age group(s) in which they serve.

Beyond the developmental needs, YD professionals should also know more personal attributes of the youth that they serve. One of the most important is to understand the culture of youth. Here, culture is used to refer both to what is currently common among youth and also one's racial/ethnic, community, and family traditions. Youth culture is best described in clichés like, "what the kids are doing these days" or "what the kids are getting into" and really captures what children and adolescents find most intriguing at the moment. YD professionals will find knowledge of youth culture useful for building rapport with young people and also for informing the design of activities. A knowledge of family, community, and racial/ethnic traditions serve similar purposes. In particular, using culturally sensitive activities, language, and actions can provide a welcoming and affirming atmosphere for youth (NRC\& IOM, 2002). Cultural knowledge in the form of racial/ethnic, community, and family traditions may also give YD professionals insights into the factors that promote youths' involvement with the program. For example, some research shows that youths' reasons to participate differ by their cultural backgrounds (Perkins, Borden, Villaruel, Carlton-Hug, Stone, \& Keith, 2007).

Walker et al. (2005) and other scholars (e.g. Stein et al., 2005) argue that YD professionals should know about the everyday experiences of the youth that they serve. A thorough understanding of youths' everyday experiences is characterized by knowing how a young person perceives the contexts and people in which (s)he interacts with. For example, a YD professional with extensive experiential knowledge of a young person would know what the youth thought of his/her teacher(s), what types of responsibility the child had at home and how the youth felt about accomplishing these duties, and important people in the young person's life. Furthermore, YD professionals should also learn more personal characteristics of youth such as their personalities, interests, challenges, and goals. As with the other aspects of this knowledge domain, experiential and personal knowledge help build relationships and design activities but they can also serve as guideposts when facilitating group work. For instance, knowing youths' emotional states and tracing it back to how they experience other contexts can help YD professionals decide which activities to pursue or how to tailor an activity to the current emotional climate of youth. 
In general, knowledge of youth is for essential designing activities that motivate young people to stay engaged, facilitating collaborative activities, and building a foundation for supportive relationships to develop. Much of this knowledge domain must be gained through experience with youth but merely being around youth is not sufficient. YD professionals must make concerted efforts to get to know youth developmentally, culturally, experientially, and personally.

\section{Knowledge of Group Facilitation}

The central tasks indicate that YD professionals often work occurs in groups, large and small, while facilitating learning. Brown \& Palinscar (1989) describe cooperative group learning as a process in which facilitators provide support, create participant structures, share responsibility, and model cognitive processes. This definition suggests that YD professionals should be familiar with the strategies or best practices used to accomplish the tasks involved in facilitating learning experiences.

Let's talk about what these group facilitation tasks may entail in a youth development program. Providing support for learning is ultimately the responsibility of the YD professional, yet, they must also understand how youth can support one another as they learn. YD professionals should also establish and maintain group norms for participating in activities. For example, in classrooms, raising your hand to speak is a normative way for students to participate in discussions. This approach may or may not be appropriate in a program setting but YD professionals should strive to find suitable ways in which youth can contribute to group activities that match the culture of the program. Sharing responsibility means that all group members are responsible for achieving the goals of the activity. YD professionals can share responsibility for program activities by balancing the amount of control that (s)he has with the amount of control given to youth. It is likely that the age and developmental stage of the children or adolescents will determine the amount of control given to youth. It is common for youth to assume more responsibility as they get older but a PYD approach supports younger children assuming some responsibility for achieving the learning goals of enrichment activities. As facilitators, YD professionals should model the behaviors and types of thinking that will prepare youth to achieve learning objectives. This can occur through discussion, examples, or even demonstrations. The key here is to provide youth with representations of the types of thinking and behaviors that will help them achieve the goals of each activity.

Group facilitation techniques will change depending on a variety of factors such as the contexts, the age of youth, and the type of activity. Even so, the key factors mentioned above will have to be addressed in almost all situations. Thus, the group facilitation domain of knowledge is characterized by an understanding of the components of cooperative group learning and promising strategies used to implement each component. Observation of program activities and reviewing practice-oriented research may provide support for a YD professional seeking to enhance their knowledge of group facilitation.

\section{Knowledge of Contexts and Organizational Systems}

Knowledge of contexts and organizational systems asks that YD professionals understand the diverse contexts that youth are encounter at a systemic level, starting with their programs. According to NRC and IOM (2002) youth programs that promote healthy development should provide: (1) physical and psychological safety; (2) appropriate structure; (3) supportive relationships; (4) positive social norms; (5) opportunities for skill building; (6) support for efficacy and mattering (7) opportunities to belong; and (8) integration of family, school, and community efforts. YD professionals can use these features as guidelines when designing 
program environments (as opposed to activities) and as standards to achieve in program implementation.

Knowledge of contexts and organizational systems is also needed to identify opportunities for the program to grow as well as any constraints that exist for expanding and improving the program. For example, YD professionals should have knowledge of the school and district regulations, school culture, and community resources that can impede and/or facilitate the implementation of the program. Imagine an existing program that serves youth who live too far to walk home after the program ends in the evening. Yet, the school district provides a "late bus" for athletes who stay after school for practice. Knowledge of the school system and how it aligns with the program can be used to solve this problem. But the solution to this dilemma involves more than just knowledge of the multiple contexts it also involves YD professionals becoming advocates for youth. In this example, it's likely that a YD professional would have to seek support and/or permission from school officials for program youth to ride the "late bus" with the athletes.

Other key contexts and organizations that youth encounter are businesses, community organizations, and their families. These contexts and organizations also provide constraints and opportunities for program implementation. For instance, some community organizations accept youth volunteers. Knowledge of the organizations and businesses within a community that welcome youth volunteers can facilitate the development of service projects within a program. Knowledge of contexts and organizational systems will most likely be gained through a combination of experience and familiarization with current research. The knowledge of particular schools, districts, businesses and organizations are probably best gained through experience within a community. However, research can also point to the features of high quality developmental settings and may also highlight common constraints and opportunities that arise within communities (e.g. Benson, 2003; Camino \& Zeldin, 2002).

\section{Specialized Youth Development Knowledge}

As mentioned previously, Shulman (1986) advanced PCK as a knowledge domain that exemplified the expertise for teaching a certain subject. Specifically, PCK emerged as a combination of content knowledge and pedagogical strategies for teaching a specific topic. In TODI, Walker et al. (2005) begin to articulate a similar type of knowledge for youth programming. They assert that a youths' learning process in activities is influenced by the interplay between the environment, the subject matter of the program activity, and the pedagogical approach. Drawing from these earlier theories, I delineate a new domain of knowledge for YD professionals, Specialized Youth Development Knowledge (SYDK). This new domain of knowledge includes the previously described foundational knowledge, topical knowledge for a given activity, and a pedagogical approach.

According to TODI, the subject matter content is the main topic of the program or activity and should determine how the activity is delivered and the roles that young people can assume (Walker et al., 2005). This definition adequately describes the type of knowledge that YD professionals should have about the topic of a given activity as part of SYDK. Nonetheless, the term topical knowledge will be used as an alternative to subject matter content. Subject matter content implies an expertise in traditional academic subjects such as math, science, English and social studies. While expertise in these areas can be useful when implementing activities they are not always necessary. In comparison, topical knowledge invokes a broader knowledge base that can include aspects of traditional academic subjects but is comprised of various themes such as video games, cooking, and poetry that can be used in program activities with youth. 
The intent is not to devalue expertise in academic subjects but to capture the tension between having in depth knowledge of one subject area and being familiar enough with a topic to shape an activity to promote skill-building. The distinction between the two terms is meant to emphasize that it is possible for YD professionals to facilitate an activity that will enhance math skills without having been a math major or improve youths' public speaking skills without having a degree in communications. Topical knowledge, then, is a general knowledge of the main content of the activity and the implications for youth involvement in the delivery of activities on the topic.

TODI also asserts that that the subject matter content (more aptly described as topical knowledge) is what attracts youth to the program, however, to design activities that appeal to young people and promote positive outcomes YD professionals must also rely on their foundational knowledge. Specifically, a YD professional would need to uphold the principles of PYD in the execution of activities and be intentional about the types of learning opportunities included in those activities to appeal to the developmental needs of youth. It is this mixture of knowledge that makes SYDK a unique domain of knowledge.

A specific pedagogy still remains undefined. The description of the central tasks of YD professional's practice highlights that group activities and collaboration are embedded in the profession. Thus, an appropriate pedagogy would be sensitive to these characteristics. Larson and Walker (2005) observed YD professionals using collaborative learning with their young people. This approach considers learning as a process that occurs through interactions with others. Larson and Walker (2005) emphasize that an experienced YD professional can guide the learning process through scaffolding, encouragement, modeling techniques and behaviors, and directing youth's attention. Yet, they critique collaborative learning for not addressing how to support emotional growth in young people. Stein et al. (2005) and Walker et al. (2005) suggest experiential learning as a pedagogy for youth programming. Experiential learning focuses on the interaction between the individual and their environment as the source for learning. This contextual interaction or experience is followed by reflection, which informs the understanding of abstract concepts (Smith, 2001). As the individual gains a deeper understanding of the concept, (s)he can apply it to new settings (Smith, 2001). Again, it's the mixture of knowledge that holds the most promise, collaborative learning techniques coupled with an experiential learning pedagogy can provide powerful learning opportunities for youth. In a combination of the two approaches, adults would guide collaborative experience, which allows youth to learn from all aspects of their environments including any emotions that may arise. Then, through reflection facilitated by a YD professional, young people would process what they learned and felt. A subsequent activity (shaped by a YD professional) would provide opportunities for youth to apply their new knowledge.

This brand of pedagogy would be incomplete without knowledge of how to structure activities that boost positive youth outcomes. Durlak and Weissburg (2007) found that S.A.F.E activities were associated with improvement in youth's personal and social skills. Programs whose activities were sequenced or scaffold youth abilities to build a particular set of skills and used active forms of learning (e.g. experience) were more likely to improve outcomes for participating youth. Furthermore, these programs included at least one component that was focused on a developmental goal and included activities that explicitly targeted a specific skill. These activities features are not meant to replace the four activity features identified by Roth and Brooks Gunn (2003a; 2003b; 2003c) rather they are intend to complement them and support implementation of activities that promote positive outcomes for youth. Therefore, 
S.A.F.E. activities along with a collaborative, experiential approach describe the instructional strategies or pedagogy that seem most suited to the central tasks of YD professionals.

Much like PCK, Specialized Youth Development Knowledge emphasizes that different domains of knowledge are combined to foster growth and development in young people. Theoretically, foundational knowledge will work with topical knowledge to inform how content will be explored and topical knowledge and the pedagogical approach are coupled to design activities. There may be more ways in which these types of knowledge work together to guide the practice of YD professionals that have not yet been identified. Even at this nascent stage, the SYDK describes a form of expert knowledge that is needed by YD professionals to implement engaging high-quality activities but it is remains unclear how to develop SYDK in the YD workforce.

\section{Discussion}

A proposed model of knowledge for YD professionals is merely a starting point and raises several research questions. Do expert YD professionals exhibit the domains of knowledge in practice? If so, what serves as evidence of the proposed knowledge domains? How does this model of knowledge relate to program quality? What are the implications of this model for recruiting, hiring, and training future YD professionals? Together these questions may be the beginning of a practice-oriented research agenda about youth development programs. Currently, the field may not be ready to provide answers to these questions. Perhaps, our first step should be to continue to articulate a model of knowledge for YD professionals. It is in this spirit that I invite others, practitioners and researchers alike, to join me, in building upon, refining, and critiquing this model in an effort to define expertise in the youth development field.

\section{References}

Astroth, K., Garza, P., \& Taylor, B. (2004). Getting down to business: Defining competencies for entry-level youth workers. New Directions for Youth Development 104, 25-37.

Ball, D., \& Cohen, K. (1999). Developing, practice, developing practitioners: Toward a practicebased theory of professional education. In G. Sykes \& L. Darling-Hammond (Eds.), Teaching as the Learning Profession: Handbook of Policy and Practice. (pp.3-32). San Francisco: Jossey Bass.

Ball, D., Thames, M., \& Phelps, G. (2008). Content knowledge for teaching: What makes it special? Journal of Teacher Education 59(5), 389-407.

Benson. P. (2003). Developmental assets and asset-building communities: Conceptual and empirical foundations. In R. Lerner \& P. Benson (Eds.) in Developmental Assets and AssetBuilding Communities: Implications for Research, Policy, and Practice. (p. 19 - 43). New York: Kluwer Academic/ Plenum Publishers.

Benson, P., Scales, P., Hamilton, S., Sesma, A., Hong, K., \& Roehlkepartain. (2006). Positive youth development so far: Core hypotheses and their implications for policy and practice. Insights and Evidence: Promoting Healthy Children, Youth, and Families, 3(1), 1-13. 
Birmingham, J., Pecham, E., Russell, C., \& Mielke, M. (2005). Shared features of highperforming after-school programs: $A$ follow-up to the TASC evaluation. Washington, DC: Policy Studies Associates, Inc.

Bodilly, S., \& Beckett, M. (2005). Making out-of-school time matter: Evidence for an action agenda. Santa Monica, CA: RAND Corporation.

Bowie, L., \& Bronte-Tinkew, J. (2006). The importance of professional development for youth workers. Child Trends Practitioner Insights Research-to-Results. (Publication \#2006-17). Washington, DC: Child Trends.

Brown, A. \& Palincsar, A. (1989). Guided, cooperative learning and individual knowledge acquisition. In L. Resnick (Ed.). Knowing, learning, and instruction. Hillsdale, NJ: Lawrence Erlbaum Associates.

Camino, L. (2005). Pitfalls and promising practices of youth-adult partnerships: Evaluator's reflections. Journal of Community Psychology, 33(1), 75-85.

Camino, L., \& Zeldin, S. (2002). Making the transition to community youth development: Emerging roles and competencies for youth-serving organizations and youth workers. In T. Burke, S.P. Curnan, J. Erickson, D. M. Hughes, N. Leon, R. Liem, et al. (Eds.), Community youth development anthology. Sudbury, MA: Institute for Just Communities, Brandeis University.

Carlsen, W. (1999). Domains of teacher knowledge. In J. Gess-Newsome \& N. Lederman (Eds.), Examining Pedagogical Content Knowledge: The Construct and its Implications for Science Education. Boston:Kluwer Academic Publishers.

Catalano, R., Berglund, M., Ryan, J., Lonczak, H., \& Hawkins, J. (2004). Positive youth development in the United States: Research findings on evaluations of positive youth development programs. Annals of the American Academy of Political and Social Science, 591, 98-124.

Durlak, J., \& Weissberg, R. (2007). The impact of after-school programs that promote personal and social skills. Chicago, IL: Collaborative for Academic, Social, and Emotional Learning.

Dworkin, J., Larson, R., \& Hansen, D. (2003). Adolescents' accounts of growth experiences in youth activities. Journal of Youth and Adolescence, 32(1), 17-26.

Eccles, J., \& Midgley, C. (1989). Stage/Environment Fit: Developmentally Appropriate Classrooms for Young Adolescents. In R. E. Ames C. Ames (Eds.), Research on Motivation and Education, (Vol. 3, pp. 139-186). New York, NY: Academic Press.

Garet, M., Porter, A., Desimone, L., Birman, B., \& Yoon, K.S. (2001). What makes professional development effective? Results from a national sample of teachers. American Educational Research Journal, 38(4), 915-945.

Grossman, J., Price, M., Fellerath, V., Jucovy, L., Kotloff, L., Raley, R., et al. (2002). Multiple choices after school: Findings from the extended-service schools initiative (No. 48).

Philadelphia: MDRC. 
Hair, E., Moore, K., Hunter, D., \& Kaye, J. (2002). Clark Youth Development Outcomes Compendium. Washington, DC: Childtrends.

Hamilton, S., Hamilton, M., \& Pittman, K. (2004). Introduction: What is youth development? In S. Hamilton \& M. Hamilton (Eds). The youth development handbook: Coming of age in American Communities. Thousands Oaks, CA: Sage.

Hawley, W.D., \& Valli, L. (1999). The essentials of effective professional development: A new consensus. In L. Darling Hammond \& G. Sykes (Eds.), Teaching as the learning profession: Handbook of policy and practice. (pp. 127-150). San Francisco: Jossey-Bass.

Huebner, A., Walker, J., \& McFarland, M. (2003). Staff development for the youth development professional: A critical framework for understanding the work. Youth \& Society, 35(2), 204-223.

King, P., Dowling, E., Mueller, R., White, K., Schultz, W., Osborn, P., et al. (2005). Thriving in adolescence: The voices of youth-serving practitioners, parents, and late adolescents. Journal of Early Adolescence, 25(1), 94-112.

Larson, R., Hansen, D., \& Walker, K. (2005). Everybody's gotta give: Development of initiative and teamwork within a youth program. In J. Mahoney, R. Larson, \& J. Eccles (Eds.), Organized activities as contest of development: Extracurricular activities, after-school and community programs. (pp. 159-184). Mahway, NJ: Lawrence Erlbaum Associates.

Larson, R., Jarrett, R., Hansen, D., Pearce, N., Sullivan, P., Walker, K., et al. (2004). Organized youth activities as contexts for positive development (pp. 540-560). In Linley, A. \& Joseph, S. (Eds.), Positive Psychology in Practice: From Research to Application, New York: Wiley.

Larson, R., \& Walker, K. (2010). Dilemmas in practice: Challenges to program quality encountered by youth program leaders. American Journal of Community Psychology.

Larson, R., \& Walker, K. (2005). Processes of positive development: Classic theories. In P. Witt and L. Caldwell (Eds.), Recreation and Youth Development. State College, PA: Venture Publishing.

Larson, R., Walker, K., \& Pearce, N. (2005). A comparison of youth-driven and adult-driven Youth programs: Balancing inputs from youth and adults. Journal of Community Psychology, 33 (1), 57-74.

Lauver, S., Little, P, \& Weiss, H. (2004). Moving beyond the barriers: Attracting and sustaining youth participation in out-of-school time programs. Issues and Opportunities in Out-of-School Time Evaluation, 6, 1-15.

Lerner, R. (2005). Promoting positive youth development: Theoretical and empirical bases. Medford, MA: Institute for Applied Research in Youth Development.

Little, P., \& Harris, E. (2003). A review of out-of-school time program quasi-experimental and experimental evaluation results (No. 1). Cambridge, MA: Harvard Family Research Project. 
Madzey-Akale, J. \& Walker, J. (2000). Training needs and professional development interests of Twin Cities youth workers: Summary. Minneapolis, MN: Regents of the University of Minnesota.

Miller, B. (2003). Critical Hours: After school programs and educational success. Brookline, MA: Nellie Mae Foundation.

National Institute on Out-of-School Time. (2006). The human services workforce initiative: setting the stage for a youth development credential. Houston, TX: Cornerstones for Kids.

National Research Council and Institute of Medicine. (2002). Community programs to promote youth development. Committee on Community-Level Programs for Youth. J. Eccles \& J.A. Gootman (Eds.), Board on Children, Youth, and Families, Division of Behavioral and Social Science and Education. Washington, DC: National Academy Press.

Perkins, D., Borden, L., Villaruel, F., Carlton-Hug, A., Stone, M., \& Keith, J. (2005). Participation in structured youth programs: Why ethnic minority urban youth choose to participate- or not to participate. Youth \& Society, 38(4), 420-442.

Phelps, E., Zimmerman, S., Warren, A., Jelicic, H., von Eye, A., \& Lerner, R. (2009). The structure and developmental course of Positive Youth Development (PYD) in early adolescence: Implications for theory and practice. Journal of Applied Developmental Psychology, 30, 571584.

Pittman, K., Irby, M., \& Ferber, T. (2001). Unfinished business: Further reflections on a Decade of promoting youth development. In P. Benson \& K. Pittman (Eds), Trends in youth development: Visions, realities and challenges. (pp. 3 -50). Boston: Kluwer Academic Publishers.

Roth, J., \& Brooks-Gunn, J. (2003a). What Exactly Is a Youth Development Program? Answers From Research and Practice. Applied Developmental Science, 72 , 94-111. doi: 10.1207/S1532480XADS0702_6.

Roth, J., \& Brooks-Gunn, J. (2003b). Youth development programs: Risk, prevention and policy. Journal of Adolescent Health, 32(3), 170-182.

Roth, J., \& Brooks-Gunn, J. (2003c). What is a youth development programs? Identification of defining principles. In R. Lerner, F. Jacobs, \& D. Wertlieb (Eds), Handbook of applied developmental science: Promoting positive childe, adolescent, and family development through research, policies, and programs: Vol. 2. Enhancing the life chances of youth and families: Public services and public policy perspectives. (pp. 197-223). Thousand Oaks, CA: Sage Publications.

Scribner, J.P. (1999). Professional development: Untangling the influence of work context on teacher learning. Educational Administration Quarterly, 35, 238-266.

Shulman, L.S. (1987). Knowledge and teaching: Foundations of the new reform. Harvard Educational Review, 57, 1-22.

Shulman, L. (1986). Those who understand: Knowledge growth in teaching. Educational Researcher, 15(2) 4-14. 
Shulman, L., \& Sykes, (1986). A national board for teaching? In search of a bold standard. Washington, DC: Carnegie Forum on Education and Economy.

Smith, M.K. (2001). 'David A. Kolb on experiential learning,' the encyclopedia of informal education, http://www.infed.org/b-explrn.htm.

Smith, C., Peck, S., Denault, A., Blazevski, J., Akiva, T. (2010). Quality at the point of service: Profiles of practice in after-school settings. American Journal of Community Psychology, 45, 358-369.

Stein, J., Wood, E., Walker, J., Kimball, E., Outley, C. \& Baizerman, M. (2005). The youth development leadership experience for youthwork practitioners. Child and Youth Care Forum 34(4), 303-325.

Stone, B., Garza P., \& Borden, L. (2004). Attracting, Developing \& Retaining Youth Workers for the Next Generation. Wingspread Conference: National Collaboration for Youth, National 4-H Headquarters, CSREES, USDA, University of Arizona School of Family and Consumer Science.

Stone, B., \& Rennekamp, R. (2004). New foundations for the 4-H Youth Development profession: 4-H professional research, knowledge, and competencies study. Chevy Chase, MD: National 4-H Professional Development Task Force, National 4-H Headquarters, Cooperative State Research Education and Extension Service, and United States Department of Agriculture.

Theokas, C., Almerigi, R., Lerner, R., Dowling, E., Benson, P., Scales, P., et al. (2005). Conceptualizing and modeling individual and ecological assets components of thriving in early adolescence. Journal of Early Adolescence, 25(1), 113-143.

Vance, F. (2010). A comparative analysis of competency frameworks for youth workers in the out-of-school time field. Child and Youth Care Forum, 39, 421-441.

Vandell, D., Reisner, E., Brown, B., Pierce, K., Dadisman, K., \& Pechman, E. (2004). The study of promising after school programs: Descriptive report of the promising programs. Madison, WI: Wisconsin Center for Education Research.

Vandell, D., Reisner, E., Brown, B., Dadisman, K., Pierce, K., Lee, D., et al. (2005). The study of promising after-school programs: Examination of intermediate outcomes in Year 2. Madison, WI: Wisconsin Center for Education Research.

Vandell, D., Reisner, E., Brown, B., Dadisman, K., Pierce, K., Lee, D., et al. (2006). The study of promising after-school programs: Examination of longer term outcomes after two years of program experiences. Madison, WI: Wisconsin Center for Education Research.

Vygotsky, L. (1962). Thought and language. Cambridge, MA: MIT Press.

Walker, K. \& Larson, R. (2006). Dilemmas of youth work: Balancing the professional and personal. New Directions for Youth Development, 112, 109-118. 
Walker, J., Marczak, M., Blyth, D., \& Borden, L. (2005). Designing youth development programs: Toward a theory of developmental intentionality. In J. Mahoney, R. Larson \& J. Eccles (Eds.), Organized Activities as Contexts of Development: Extracurricular Activities, AfterSchool and Community Programs. (pp. 399-419). Mahway, NJ: Lawrence Erlbaum Associates.

Wilson, S., Shulman, L., \& Richert, A. (1987). "150 different ways of knowing": Representations of knowledge in teaching. In J. Calderhead (Ed.), Exploring teachers' thinking. (pp. 104-123). Eastbourne, UK: Cassell.

Yohalem, N. (2003). Adults who make a difference: Idenfity the skills and characteristics of successful youth workers. In F. Villarruel, D. Perkins, L. Borden, \& J. Keith (Eds.), Community Youth Development: Programs, Policies and Practices. (pp. 358-372). Thousand Oaks, CA:

Sage.

Yohalem, N., Pittman, K., \& Edwards, S. (2010) Strengthening the Youth Development/AfterSchool Workforce: Lessons Learned and Implications for Funders. Washington, DC: The Forum for Youth Investment and Cornerstones for Kids.

Yohalem, N., Pittman, K., \& Moore, D. (2006). Growing the next generation of youth professionals: Workforce opportunities and challenges. Houston, TX: Cornerstones For Kids.

(C) Copyright of Journal of Youth Development $~$ Bridging Research and Practice. Content may not be copied or emailed to multiple sites or posted to a listserv without copyright holder's express written permission. However, users may print, download or email articles for individual use. 